\title{
Reabilitação facial por meio de prótese oculopalpebral
}

Facial rehabilitation through oculopalpebral prosthesis

Rehabilitación facial através de la prótesis oculopalpebral

Bárbara Sousa DA SILVA ${ }^{1}$

Thaysa Cristina Batista DE MATTOS ${ }^{1}$

Erika Akiko Moura SHIOTA ${ }^{2}$

Sybilla Torres DIAS ${ }^{3}$

Cristiane Maria Brasil LEAL ${ }^{3}$

Brigitte NICHTHAUSER ${ }^{3}$

${ }^{l}$ Graduanda em odontologia pela Universidade do Estado do Amazonas (UEA), 69065-001 Manaus-AM, Brasil

Cirurgiã-Dentista, 69065-001 Manaus-AM, Brasil

${ }^{3}$ Departamento de Prótese Total e Bucomaxilofacial da Universidade do Estado do Amazonas (UEA), 69065-001 Manaus-AM, Brasil

\section{Resumo}

A prótese bucomaxilofacial visa a reabilitação de pacientes que sofreram mutilações na face, restituindo estética e autoestima. Este trabalho visa relatar o caso clínico de um paciente reabilitado com prótese oculopalpebral após sofrer exenteração de órbita, decorrente de um carcinoma espinocelular em pálpebra inferior direita. Paciente, gênero masculino, 56 anos, procurou atendimento odontológico queixando-se de desconforto estético do rosto. Ao exame clínico foi observada ausência do globo ocular, pálpebras e arco superciliar do lado direito, por isto, foi planejada a confecção de uma prótese oculopalpebral. Foi realizada moldagem dos terços superior e médio da face, obteve-se o molde em alginato e, posteriormente, o modelo em gesso. Em seguida, foi confeccionado um globo ocular caracterizado em resina acrílica termopolimerizável. Posteriormente realizou-se, sobre o modelo de gesso, a escultura da área amputada utilizando-se plastilina e cera e após prova e ajustes no paciente, inclusão do conjunto modelo/escultura em mufla e contramufla, com posterior eliminação da peça esculpida. Foi selecionada a cor da pele do paciente e misturou-se uma base ao silicone, que foi incluído na mufla para prensagem. Após a vulcanização do silicone, foram realizados os acabamentos, caracterização e instalação da prótese. Na proservação o paciente relatou grande satisfação com a reconstituição da estética facial. Conclui-se que a prótese bucomaxilofacial é uma alternativa satisfatória para a reabilitação de pacientes que sofreram mutilações faciais, pois restabelece a estética facial, autoestima e convívio social.

Descritores: Prótese Maxilofacial; Olho Artificial; Reabilitação; Carcinoma de Células Escamosas.

\section{Abstract}

The maxillofacial prosthesis aims at the rehabilitation of patients that suffered mutilations at the face, bringing aesthetics and self-esteem. This study aimed to report a clinical case of patient rehabilitated with oculopalpebral prosthesis after the orbital exenteration surgery, resulting from a squamous cell carcinoma in the lower right eyelid. Male patient, 56 years old, sought for dental treatment complaining of aesthetic issue in the face. Clinical examination revealed absence of the ocular globe, eyelids and right superciliary arch, so, was planned manufacture of an oculopalpebral prosthesis. A molding was executed in the superior and middle thirds of the face, obtaining the impression in alginate and, later, the model in dental gypsum. Thereafter, an ocular globe was manufactured and characterized using thermopolymerized acrylic resin. Subsequently, was sculpted over the gypsum model the absent area in plastiline and dental wax; after patient tests was made adjustments, inclusion of the model/sculpture set in the muffle and counter-mufle, followed by elimination of the sculpture. The patient's skin color was selected to use a liquid foundation that was mixed with silicone and it was included in the press muffle. After the vulcanization of the silicone, the prosthesis finishing, its characterization and installation were performed. At the follow-up, the patient reported a great satisfaction with the reconstitution of facial aesthetics. It's concluded that the maxillofacial prosthesis is a satisfactory alternative for the rehabilitation of patients who suffered face mutilations, restoring facial aesthetics, self-confidence and social well-being.

Descriptors: Maxillofacial Prosthesis; Eye, Artificial; Rehabilitation; Carcinoma, Squamous Cell.

\section{Resumen}

La prótesis bucomaxilofacial tiene como objetivo la rehabilitación de pacientes que sufrieron mutilación en el rostro, devolviéndole estética y autoestima. Este trabajo relata el caso clínico de un paciente rehabilitado con prótesis oculopalpebral después de sufrir exenteración de la órbita, consecuencia de un carcinoma espinocelular en el párpado inferior derecho. Paciente, género masculino, 56 años, buscó el servicio de odontología por molestias estéticas en su rostro. Al examen clínico se observó ausencia del globo ocular, párpado y arco superciliar del lado derecho, se planificó la confección de una prótesis oculopalpebral. Se realizó la impresión de los tercios superiores y medio de la cara, se obtuvo el molde en alginato, posteriormente, el moldelo de yeso. Luego fué confeccionado un globo ocular personalizado en resina acrílica termopolimerizable. Posteriormente se realizó, sobre el modelo de yeso, la escultura del area amputada en plastilina y cera, seguido de prueba y ajustes en paciente, inclusión del conjunto modelo y escultura en mufla e contra-mufla, con posterior eliminación de la pieza esculpida. Se seleccionó el color de la piel del paciente e se mezcló una base con el silicón que fué incluido en la mufla para prensa. Después de la vulcanización del silicón, fueron realizados acabados, caracterización e instalación de la prótesis. En la consulta de revisión el paciente relato gran satisfacción por la reconstrucción de la estética facial. Conclúyese que lá prótesis bucomaxilofacial es una alternativa satisfactória para la rehabilitación de pacientes que sufrieron mutilación facial, porque restablece la estética facial, autoestima e vida social.

Descriptores: Prótesis Maxilofacial; Ojo Artificial; Rehabilitación; Carcinoma de Células Escamosas.

INTRODUÇÃo

Próteses faciais são elementos artificiais que substituem uma ou mais partes do rosto como olhos, orelhas e narizes, ausentes desde o nascimento ou amputadas em decorrência de queimaduras, traumas ou cânceres. Estas podem ser artística e tecnicamente projetadas para restaurar forma e função, bem como harmonizar com as proporções da face ${ }^{1}$. Em pacientes submetidos a tratamento oncocirúrgico que provocaram deformações na face, as próteses faciais muitas vezes são a única alternativa de reabilitação, visto que a cirurgia plástica reparadora pode ser contraindicada em função de condições sistêmicas desfavoráveis, impossibilidade de reconstrução de estruturas anatômicas perdidas, morbidade em áreas doadoras e receptoras de enxerto além do fato de muitas vezes serem pacientes oncológicos irradiados ${ }^{2,3}$

O carcinoma espinocelular, também chamado de carcinoma de células escamosas, é um dos diferentes tipos de câncer que se desenvolvem na pele. Tem origem na camada mais superficial da epiderme e, em geral, atinge áreas do corpo expostas ao sol, como rosto, orelhas, pescoços, lábios e dorso das mãos. Dependendo da localização e do tamanho, 
o tratamento do carcinoma espinocelular é realizado por meio de cirurgia seguida ou não de quimioterapia ou radioterapia4. Na região de cabeça e pescoço, a cirurgia pode resultar em desfigurações faciais difíceis de reparação com cirurgia plástica reparadora, o que pode levar a problemas de imagem corporal e disfunções ${ }^{5,6}$.

Nos casos de impossibilidade de reabilitação por meio cirúrgico, a utilização de próteses bucomaxilofaciais, tornam-se extremamente benéficas para o restabelecimento da estética facial, melhora da aceitação social, estado psicológico, autoconfiança e qualidade de vida dos pacientes ${ }^{3,5,7}$.

A prótese oculopalpebral é um tipo de prótese bucomaxilofacial que visa reabilitar paciente que perdeu além do globo ocular, tecidos adjacentes como pálpebras, músculos, pele e osso gerando ao paciente grande impacto estético, funcional, social e psíquico $^{2}$. O defeito cirúrgico envolvendo o globo ocular faz com que $\mathrm{o}$ indivíduo tenha um comprometimento funcional e estético. Para alguns pacientes, o reparo estético de defeitos específicos na cabeça e no pescoço é tão importante quanto o tratamento curativo ${ }^{7}$, entretanto a reprodução de cor natural, tamanho, contorno e orientação em uma prótese ocular que confere uma aparência de vida é um desafio para o protesista ${ }^{8}$.

Próteses faciais de silicone têm sido propostas como as melhores abordagens para reabilitação de pacientes com defeitos craniofaciais, entretanto a longevidade e manutenção destas próteses são as principais preocupações dos clínicos e dos pacientes que receberão a reabilitação ${ }^{9,10}$. Esta deve ser confeccionada de modo a respeitar as etapas clínicas e laboratoriais e realizando todos os ajustes para que fique esteticamente satisfatória. Com isso, o cirurgião-dentista deve ter a destreza e ser cuidadoso com o olhar, pois harmonizar as proporções da face pode ser uma difícil tarefa e deve ser planejada e executada cuidadosamente.

Considerando que a especialização de PBMF é relativamente recente e que há escassez de livros e artigos sobre o assunto, torna-se relevante publicações que relatem casos clínicos descrevendo o passo a passo de uma reabilitação com PBMF. Sendo assim, este artigo tem o objetivo de relatar um caso clínico de paciente reabilitado com prótese óculopalpebral após sofrer exenteração orbitária, decorrente de um carcinoma espinocelular em pálpebra inferior direita.

\section{CASO CLÍNICO}

Paciente do sexo masculino, 56 anos, leucoderma, agricultor, compareceu a Policlínica Odontológica da Universidade do Estado do Amazonas (UEA) queixando-se de desconforto estético facial. Durante a anamnese, verificou-se um histórico oncológico, em que o paciente relatou que há 5 anos, foi diagnosticado com tumor maligno invasivo na órbita direita, realizou biópsia que diagnosticou carcinoma espinocelular moderadamente diferenciado, localizado na pálpebra inferior. Realizou cirurgia de exenteração da órbita direita e no mesmo ano recebeu um enxerto livre de face interna do antebraço para recobrimento da cavidade remanescente. Dois anos após diagnóstico realizou cirurgia de esvaziamento cervical e posteriormente iniciou o tratamento de radioterapia na Fundação Centro de Controle de Oncologia do Amazonas (FCECON), com um total de 35 sessões. Ao exame clínico verificou-se ausência do globo ocular, pálpebras e arco superciliar do lado direito da face, sem exposição das mucosas devido ao preenchimento com enxerto (Figura 1).

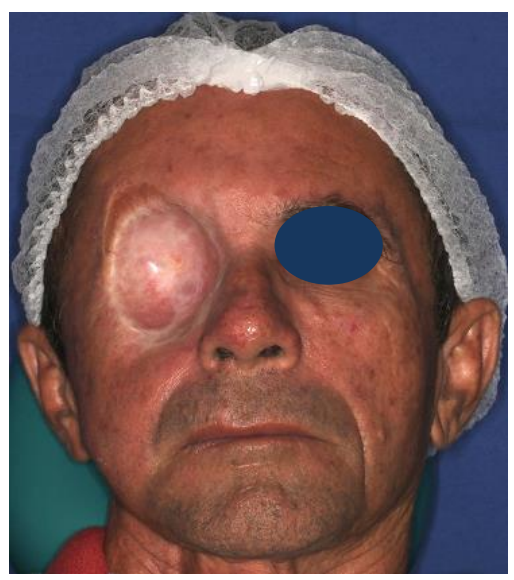

Figura 1: Aspecto clínico inicial

Nesse cenário, optou-se pela confecção de uma prótese oculopalpebral do lado afetado. Previamente à moldagem, aplicou-se vaselina na sobrancelha e cílios para facilitar a remoção do material posteriormente. Foi realizada moldagem anatômica dos terços superior e médio da face com hidrocolóide irreversível, retenções com algodão e uma base de gesso comum (Tipo II) como suporte do material para obtenção do molde (Figuras 2 e 3 ). Com isso foi obtido o modelo de trabalho em gesso especial - tipo IV. No modelo obtido, sobre a área a ser reabilitada, foi confeccionada uma base de cera 7 vermelha a fim de abrigar a plastilina utilizada para a escultura da região (Figura 4).

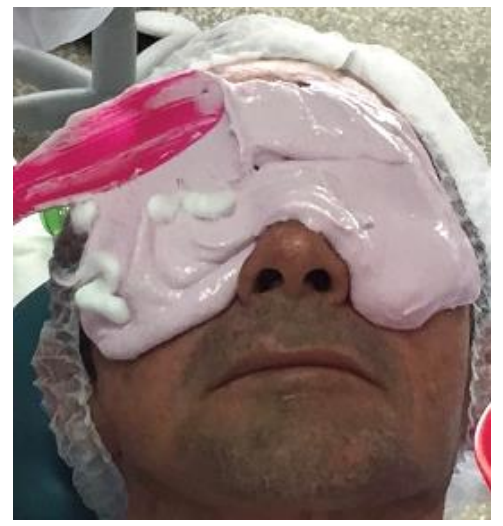

Figura 2: Moldagem dos terços superior e médio da face. 


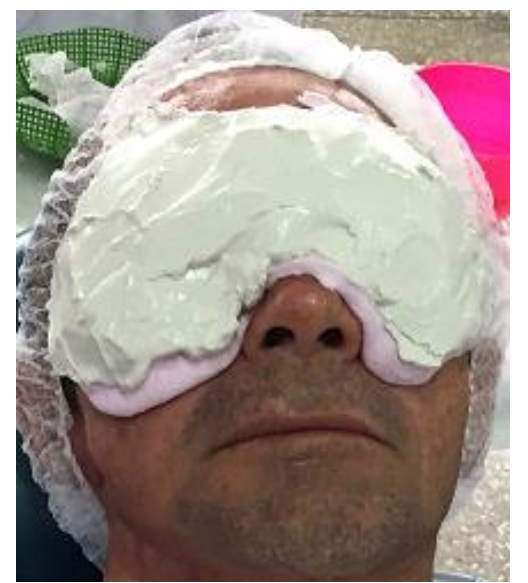

Figura 3: Base em gesso para suporte do alginato.

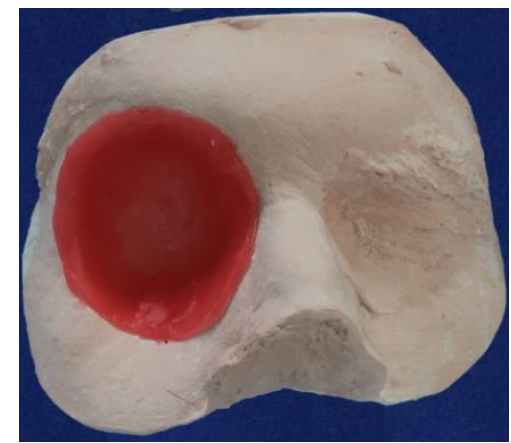

Figura 4: Modelo com base de cera 7

Outro passo laboratorial foi a confecção da prótese ocular, que consistiu na utilização de uma calota em resina acrílica termopolimerizável e pintura com tinta a base d'água para a caracterização da íris. $\mathrm{O}$ processo foi realizado observando a cor e características do olho do paciente (Figura 5). Em seguida, foi feita a escultura palpebral, com ajustes e provas no paciente para melhor reprodução e detalhamento das estruturas (Figuras 6 e 7). Na sequência laboratorial procedeu-se à inclusão do modelo na mufla e contramufla (Figura 8) e posterior eliminação da cera/plastilina para que o silicone caracterizado pudesse ser prensado.

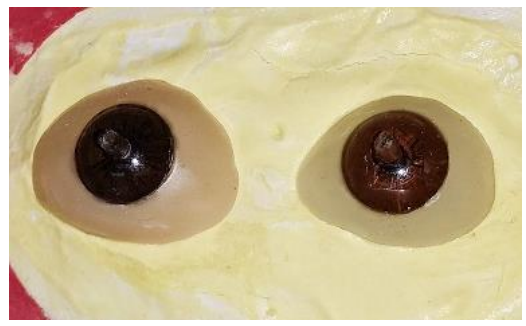

Figura 5: Prótese ocular caracterizada.

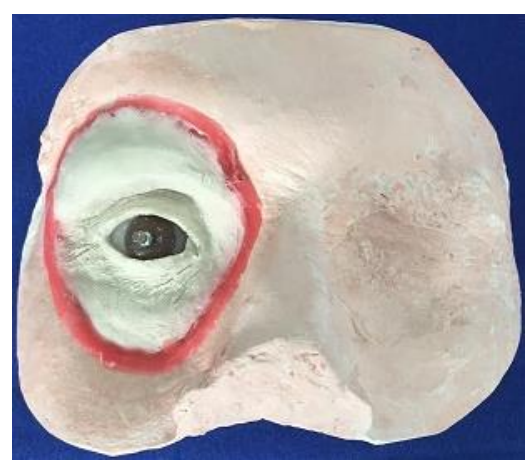

Figura 6: Escultura palpebral em plastilina finalizada.

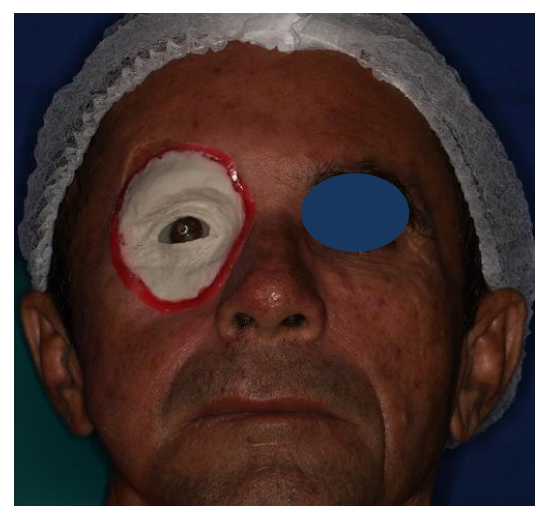

Figura 7: Prova da escultura e últimos ajustes.

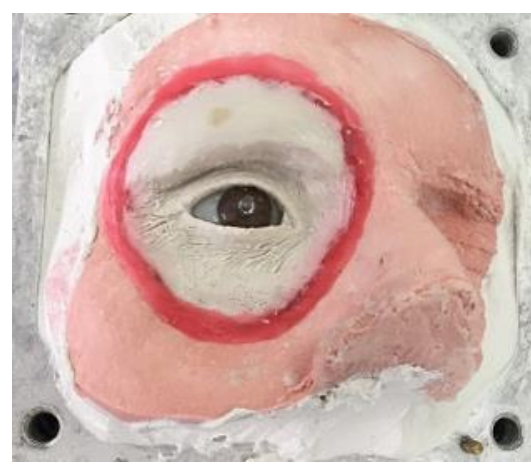

Figura 8: Inclusão do modelo na mufla.

Para a coloração da prótese foi utilizada uma base de maquiagem cosmética de pele, selecionando a cor que mais se aproximou ao tom da pele do paciente. Após a seleção, a base foi misturada com o silicone elastomérico atóxico, bi-componente semicristal e comparada com a pele do paciente, até atingir o tom ideal. Para caracterizar cor e textura de pele foram adicionadas fibras coloridas para efeitos artísticos (flocking). Após a mistura, introduziu-se o silicone caracterizado na mufla/contramufla e foi realizada a prensagem (Figura 9).

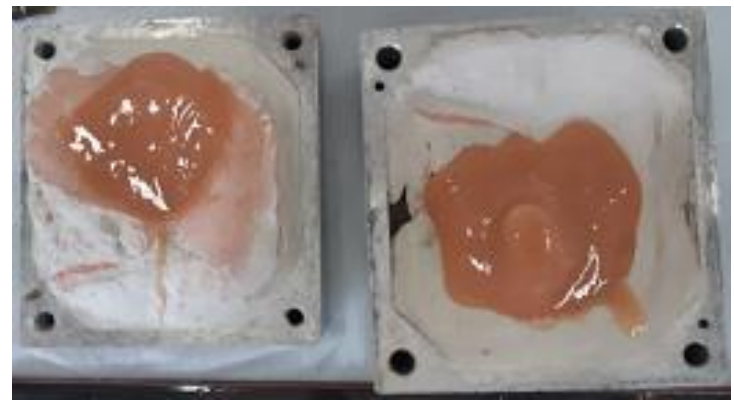

Figura 9: Inclusão do silicone na mufla e contramufla

O tempo de presa inicial foi de uma hora, porém a abertura da mufla se deu somente após 24 horas para assegurar completa vulcanização do material, quando então foram realizados os ajustes como recorte de excessos e eliminação de bolhas positivas (Figura 10). As caracterizações de sobrancelhas, sinais e manchas da pele (Figuras 11) foram feitas com refinamento, a fim de garantir a fidelidade de semelhança com o lado antagonista. Tais características foram adicionadas na presença do paciente, em etapa clínica, intercalando-se com provas da prótese (Figura 12). O paciente foi 
instruído acerca da importância dos métodos de retenção, como a utilização de cola para prótese e de óculos, além das instruções de higiene. Neste momento, apesar da falta de algumas caracterizações, a prótese foi instalada no paciente para que o mesmo já pudesse se adaptar com a sua utilização e verificar possíveis dificuldades e/ou necessidade de ajustes. Uma semana depois, foi feita a inserção dos cílios artificiais e a primeira proservação (Figuras 13 e 14), na qual o paciente relatou satisfação com a utilização da prótese, com a estética e retenção. Posteriormente foram realizadas mais duas sessões de proservação, com intervalo de um mês depois e de dois meses (Figura 15).

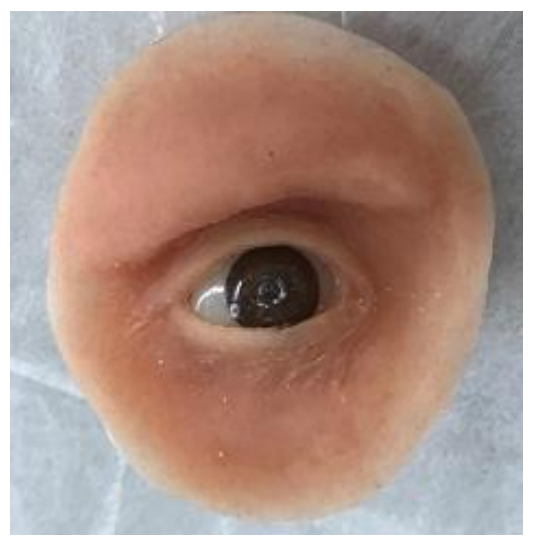

Figura 10: Prótese após ajustes iniciais.

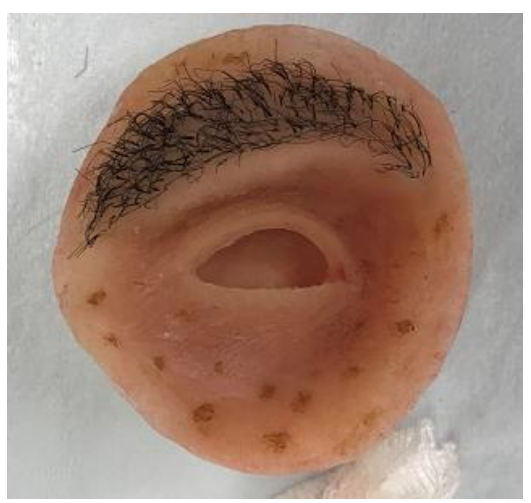

Figura 11: Prótese após inserção da sobrancelha artificial e caracterização de manchas com pigmentos

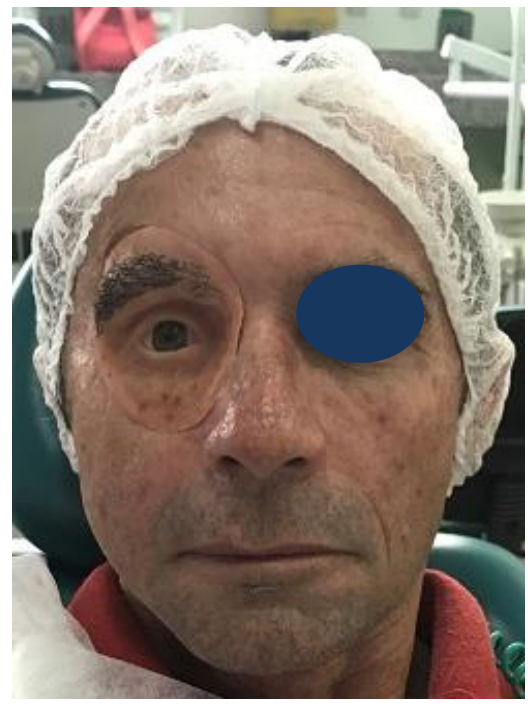

Figura 12: Prova da prótese.

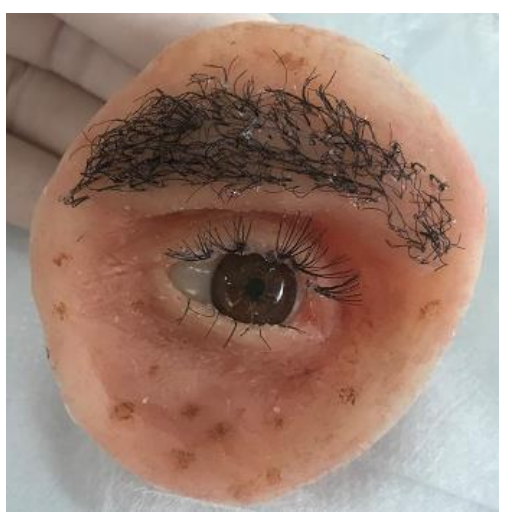

Figura 13: Caracterização final da prótese com aplicação de cílios artificiais.

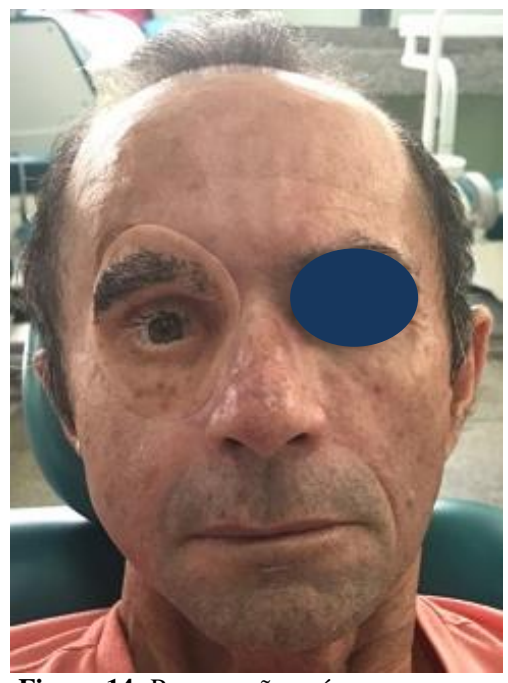

Figura 14: Proservação após uma semana.

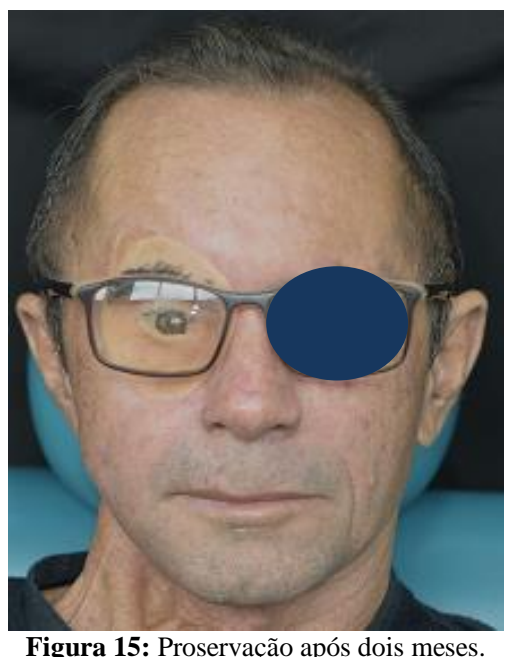

DISCUSSÃO

Segundo Soares et al. $^{11}$ o carcinoma espinocelular é o segundo tumor maligno mais frequente na pálpebra, correspondendo a $12,76 \%$ dos tumores malignos das pálpebras. Ainda nos estudos de Soares et al. ${ }^{11}$, de 7 pacientes com carcinoma espinocelular, 4 ocorreram em pálpebra inferior (57,14\%), 2 acometeram pálpebra superior e inferior $(28,57 \%)$ e apenas 1 acometeu pálpebra superior $(14,28 \%)$, o que corrobora com Petsuksiri et al.4 (2008), que também apontou em seu estudo a pálpebra inferior como o local mais comum 
acometido pelo tumor. Neste relato de caso o paciente foi diagnosticado com carcinoma espinocelular moderadamente diferenciado, localizado na pálpebra inferior.

Segundo Grant et al. ${ }^{12}$, a confecção de uma prótese facial é um processo difícil tanto para o provedor, quanto para o paciente e requer várias visitas envolvendo procedimentos desconfortáveis e estressantes, fato comprovado clinicamente, pois paciente mostrou-se ansioso na espera pela conclusão do tratamento. Entretanto, na técnica utilizada, apenas a moldagem anatômica eventualmente causou certo desconforto, visto que os demais procedimentos, apesar de longos, não interferiram no bem-estar do paciente.

A prótese bucomaxilofacial é confeccionada para trazer qualidade de vida ao paciente ${ }^{3,6}$. De acordo com Sohaib et al. ${ }^{13}$, é importante obter uma reprodução precisa das cores, pois aparência natural e realista é primordial para os pacientes e isso influencia na qualidade das próteses, trazendo melhorias em status social, emocional e psicológico. Segundo Wondergem et al. ${ }^{7}$, a maioria dos pacientes se sentiu bastante satisfeita ou até mesmo muito satisfeita com a cor de suas próteses e nenhum estava insatisfeito. Tal aspecto foi observado no momento da instalação da prótese, onde o paciente tratado mostrou bastante agradado com o resultado final.

Elastômeros de silicone são os materiais mais usados para próteses maxilofaciais devido às suas propriedades físicas, capacidade de aceitar coloração intrínseca e extrínseca e possui semelhança com a elasticidade da pele, de acordo com ponderação de Koyama et al. ${ }^{10}$. Veerareddy et al. ${ }^{14}$ relatou ainda, que o silicone é preferido para fabricação de próteses orbitais, uma vez que a adaptação marginal e aparência natural do material são superiores. Não obstante, Bellamy et al. ${ }^{15}$ discorreu que, embora amplamente utilizados, esses materiais estão longe de serem ideais e pouco trabalho foi feito em desenvolvimento de novos materiais. Concordou-se com ambos os autores no tocante à preferência do uso de silicone para a fabricação da prótese e ao mesmo tempo não sendo possível obter mais opções de materiais testados clinicamente.

Em relação aos métodos de retenção, Papaspyrou et al. ${ }^{16}$ expuseram quatro técnicas de ancoragem de prótese disponíveis: o anatômico (usando estruturas já existentes), o mecânico (armações de óculos), o químico (usando adesivos) e a ancoragem cirúrgica (utilizando implantes de titânio). Brandão et al. ${ }^{9}$ enfatizaram ainda que a retenção da prótese é assumida como sendo o determinante primário de uma abordagem de sucesso e tem sido tradicionalmente alcançada usando adesivos ou óculos. No entanto, nenhum desses métodos fornece retenção satisfatória e duradoura. Nos estudos de Chang et al. ${ }^{17}$, a maioria dos participantes que faziam uso de próteses adesivas relatou classificações positivas em relação à retenção, conforto, aparência, ajuste e de não irritação. No presente estudo foi utilizado adesivo, como cola para prótese e a armação dos óculos que o paciente já utilizava. Na proservação após dois meses, foi verificado que os métodos de retenção utilizados apresentaram-se satisfatórios.

Para Duncan e Calhoun ${ }^{1}$, a pele cicatrizada e enxertada pode reagir de maneira diferente do que a pele normal debaixo de uma prótese, pois pode haver rigidez. Um ajuste inadequado pode resultar em irritação do tecido ou mesmo avaria. Já para Nomura et al. ${ }^{18}$, com um selamento forte entre a prótese e a pele, a prótese também pode ser um eficaz dispositivo de tratamento de feridas no pósoperatório precoce. Para Dings et al. ${ }^{19}$, não foram encontradas diferenças estatisticamente significantes na prevalência de complicações dos tecidos moles em relação à diferentes mecanismos de retenção. Não foram notados quaisquer problemas em relação a adaptação ao tecido paciente. A pele reagiu de maneira favorável tanto à prótese quanto ao adesivo utilizado para reter a mesma.

Segundo Ariani et al. ${ }^{20}$, a limpeza de uma prótese facial (com ou sem cola) ou da pele (com ou sem implante) pode ser uma tarefa difícil, especialmente para pacientes com destreza manual limitada ou problemas visuais, o que é comum em idosos que apresentam o maior grupo entre os usuários de próteses faciais. Neste estudo, constatouse que é possível higienizar a prótese facial de silicone embebendo-a em clorexidina, a qual mostrou-se altamente eficaz. Tal procedimento deve ser repetido diariamente para a limpeza e redução de irritação da pele causada pelos microorganismos. No entanto, por ser mais acessível, optou-se por instruílo a utilizar água e sabão neutro, que apesar de não ser tão eficaz quanto a clorexidina, ainda assim, traz higienização satisfatória.

No estudo de Goiato et al..$^{21}$ foi relatado que a vida útil das próteses faciais é resultado da degradação do elastômero e instabilidade da cor. A deterioração pode ser causada por muitos fatores, incluindo exposição ambiental e mudanças de umidade, além do manuseio e limpeza realizados pelo paciente, o que corrobora com os estudos de Jeibrel $^{22}$ que ponderou que a maioria dos pacientes renovava suas próteses orbitais a cada 6 a 9 meses. Por ser de confecção recente, ainda não foi possível observar o aspecto da vida útil da prótese em silicone neste caso clínico relatado.

\section{CONCLUSÃO}

As próteses bucomaxilofaciais são uma escolha de tratamento bem-sucedido para pacientes mutilados faciais que sofrem com problemas funcionais ou estéticos, fazendo com que o uso de 
uma prótese facial tenha impacto positivo na autoestima, convívio social e qualidade de vida dos pacientes. No caso clínico relatado, a prótese oculopalpebral trouxe satisfação ao paciente, restabelecendo forma, anatomia e estética da face além de devolver-lhe o bem-estar físico, psicológico e emocional. O paciente se mostrou receptivo aos métodos de retenção e às instruções de manutenção da prótese.

\section{REFERENNCIAS}

1. Duncan BGF, Calhoun ME. Facial prostheses in the rehabilitation of burn patients. Nurse Life Care Planner. 2015;15(3):900-5.

2. Vieira LM, Oguro P, Dias RB, Pimentel ML, Barretto MRP, Coto NP. Proposition of integrated electrical mechanism anda facial prosthesis for eyelid motion on prosthetic oculopalpebral rehabilitation: technical note. Biosci.J. 2019; 35(2):659-65.

3. Moss OB, Pinheiro BCL, Mendes TCC, Braga FP, Nichthauser B, Leal CMB. Reabilitação oral com prótese bucomaxilofacial em paciente pediátrica submetida à excisão de lesão neoplásica benigna em maxila. Arch Health Invest. 2019;8(11):706-10.

4. Petsuksiri J, Frank SJ, Garden AS, Ang KK, Morrison WH, Chao KS, Rosenthal DI, Schwartz DL, Ahamad A, Esmaeli B. Outcomes after radiotherapy for squamous cell carcinoma of the eyelid. Cancer. 2008;112(1):111-18.

5. Dib LL, Oliveira JAP. Reabilitação Bucomaxilofacial - uso de próteses e implantes osseointegrados. In: Cardoso RJA, Gonçalves EAN. Odontologia: arte, ciência e técnica. 6 ed. São Paulo: Artes Médicas; 2002.

6. Pinheiro BCL, De Mattos TCB, Dias ST, Braga FP, Leal CMB, Nichthauser B. Reabilitação com prótese ocular em paciente anoftálmico. Full Dent. Sci. 2020;11(42):98-103.

7. Wondergem M, Lieben $\mathrm{G}$, Bouman S, van den Brekel MW, Lohuis PJ. Patients' satisfaction with facial prostheses. Br J Oral Maxillofac Surg. 2016;54(4):394-9.

8. Lanzara R, Thakur A, Viswambaran M, Khattak A. Fabrication of ocular prosthesis with a digital customization technique - a case report. J Family Med Prim Care. 2019;8(3):1239-42.

9. Brandão TB, Filho AJV, Batista VES, Ribeiro ACP, Nary Filho H, Chilvarquer I, et al. Assessment of treatment outcomes for facial prostheses in patients with craniofacial defects: A pilot retrospective study. J Prosthet Dent. 2017;118(2):235-41.

10. Koyama S, Sasaki K, Hanawa S, Sato N. The potential of cohesive silicone for facial prosthetic use: a material property study and a clinical report. J Prosthodont. 2011;20(4):299-304.
11. Soares LHS, Bello CV, Reis AKL, Nunes RR, Mason EM. Tumores malignos de pálpebra. Arq Bras Oftalmol. 2001;64(1):287-9.

12. Grant GT, Aita-Holmes C, Liacouras P, Garnes J, Wilson WO Jr. Digital capture, design, and manufacturing of a facial prosthesis: Clinical report on a pediatric patient. J Prosthet Dent. 2015;114(1):138-41.

13. Sohaib A, Amano K, Xiao K, Yates JM, Whitford $\mathrm{C}$, Werger S. Colour quality of facial prostheses in additive manufacturing. Int J Adv Manuf Technol. 2018; 96(2):881-94.

14. Veerareddy C, Nair KC, Reddy R. Simplified Technique for Orbital Prosthesis fabrication: a case report. J Prosthodont. 2012;21(1):561-68.

15. Bellamy K, Limbert G, Waters MG, Middleton J. An elastomeric material for facial prostheses: synthesis, experimental and numerical testing aspects. Biomaterials. 2003;24(27):5061-66.

16. Papaspyrou G, Yildiz C, Bozzato V, Bohr C, Schneider M, Hecker D, Schick B, Al Kadah B. Prosthetic supply of facial defects: long-term experience and retrospective analysis on 99 patients. Eur Arch Otorhinolaryngol. 2018;275(2):607-13.

17. Chang TL, Garrett N, Roumanas E, Beumer J 3rd. Treatment satisfaction with facial prostheses. J Prosthet Dent. 2005;94(3):275-80.

18. Nomura T, Sato J, Matsuura M, Kawaguchi K, Sekiguchi R, Horie A, Seto K. Lightweight acrylic resin facial prosthesis for maxillofacial defects: a fabrication and retention method. J Prosthet Dent. 2013;110(4):326-30.

19. Dings JPJ, Merkx MAW, de Clonie MaclennanNaphausen MTP, van de Pol P, Maal TJJ, Meijer GJ. Maxillofacial prosthetic rehabilitation: A survey on the quality of life. J Prosthet Dent. 2018;120(5):780-86.

20. Ariani N, Visser A, Teulings MR, Dijk M, Rahardjo TB, Vissink A, van der Mei HC. Efficacy of cleansing agents in killing microorganisms in mixed species biofilms present on silicone facial prostheses--an in vitro study. Clin Oral Investig. 2015;19(9):2285-93.

21. Goiato MC, Pesqueira AA, dos Santos DM, Zavanelli AC, Ribeiro Pdo P. Color stability comparison of silicone facial prostheses following disinfection. J Prosthodont. 2009;18(3):242-44.

22. Jebreil K. Accetability of orbital prostheses. J Prosthet Dent. 1980;43(1):82-5. 


\section{CONFLITO DE INTERESSES}

Os autores declaram não haver conflitos de interesse.

\section{AUTOR PARA CORRESPONDÊNCIA}

Cristiane Maria Brasil Leal

Rua Virolas, 137 - Conj. Kissia - Bairro D. Pedro

69040-360 Manaus - AM, Brasil

cbleal@uea.edu.br

Submetido em 29/06/2020

Aceito em 14/10/2020 